\title{
Çok Düzlemli Kaynaklı K-Birleşimlerin Dayanımları
}

\author{
Resistance of Multiplanar Welded K-Joints
}

\author{
Emre ÖZYURT*1,a

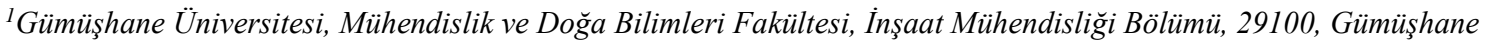

\author{
• Geliş tarihi / Received: 22.01.2020 • Düzeltilerek geliş tarihi / Received in revised form: 06.08.2020 • Kabul tarihi / Accepted: 12.08 .2020
}

\section{$\ddot{O} z$}

Boru enkesitli çelik profillerin yaygın olarak kullanılmaya başlanmasındaki önemli sebeplerden biri mimari açıdan estetik görünüme sahip olmaları, diğeri ise mühendislik avantajlarıdır. Bu yüzden, kullanım alanları çok geniştir, örneğin açık deniz yapıları, havaalanları, sergi salonları, köprüler, stadyumlar, vb. Bu tip yapılarda, çok düzlemli kaynaklı K-birleşimlerinden oluşan uzay kafes sistemler kullanılmaktadır. Ancak boru enkesitli profillerden oluşmuş, çok düzlemli kaynaklı K-birleşimlerin tasarım yöntemi, yeni çelik yapı yönetmeliğinde mevcut değildir. Bu çalışmanın amacı, yönetmelikteki düzlem kafes sistemleri için mevcut birleşim yönteminin, çok düzlemli K-birleşimler için uygun olup olmadığını incelemektir. Bu çalışma, doğrusal olmayan sonlu elemanlar yöntemi kullanılarak gerçekleştirilmiştir. Sayısal analizlerden önce sonlu elemanlar modeli mevcut bir test ile karşılaştırılarak doğrulaması yapılmıştır. Doğrulama çalışmasında belirlenen eleman ağ aralığı, eleman tipi, mesnet sınır koşulları ve yükleme yöntemine göre bir dizi parametrik çalışma yapılmıştır. Parametrik çalışmalarda, dayanım kriteri, başlık ve örgü elemanlarının geometrik özellikleri ve başlık ile örgü elemanı arasındaki açının etkileri incelenmiştir. Sayısal analiz sonuçlarına göre, mevcut yönetmelikteki düzlem K-birleşim yöntemleri aynı zamanda çok düzlemli K-birleşimlerinin dayanımlarını hesaplamak için kullanılabilir. Çok düzlemli K-birleşimlerinin dayanımlarını belirlemek için Lu'nun deformasyon sınırlaması kullanılabilir. Başlık elemanına etkiyen ekstra eksenel yükler birleşimin dayanımını etkileyebilir.

Anahtar kelimeler: Boru Enkesitli Profiller, Çok Düzlemli Birleşimler, K-birleşim, Sonlu Eleman Yöntemi, Uzay Kafes

\begin{abstract}
One of the important reasons for the popularity of circular hollow sections is an aesthetic appearance in terms of architectural point of view and engineering advantages. Therefore, they have been widely used, such as offshore structures, airports, exhibition halls, bridges, stadiums, etc. In such structures, space trusses consist of multiplanar Kjoints. However, there is no available design method of multiplanar K-joints made of circular hollow sections in the new steel structure design guide. The purpose of this study is to examine whether the current method of planar K-joint in the design guide is suitable for multiplanar K-joints. This study was carried out by using a nonlinear finite element method. Before the parametric study, the finite element model was validated against the test results. Mesh size, element type, boundary conditions and loading method determined based on the validation study were used in a series of parametric analyses. In parametric studies, the effects of the strength criterion, the geometric parameters of the chord and brace members, and the angle between the chord and brace members were examined. According to the results of numerical analysis, the planar $K$-joint methods in the current design guide can also be used to calculate the strengths of multiplanar K-joints. Lu's deformation limit can be used to determine the resistance of multiplanar K-joints. The additional axial loads in the chord member may affect the resistance of joints.
\end{abstract}

Keywords: Circular Hollow Section, Multiplanar Joints, K-joints, Finite Element Method, Space Truss

\footnotetext{
*a Emre ÖZYURT; emre.ozyurt@gumushane.edu.tr; Tel: (0456) 233 10 00; orcid.org/0000-0002-1465-596X
} 


\section{Giriş}

Çok düzlemli ve ara uzaklıklı K-birleşimleri, uzay kafesler ve açık deniz platformlarının yapımında yaygın olarak kullanılmaktadır. Çok düzlemli birleşimlerde, boru enkesitli profiller, estetik görünüş ve mühendislik avantajlarından ötürü en yaygın kullanılan profil türüdür. Boru enkesitli profillerden yapılmış çok düzlemli $\mathrm{K}$ birleşimlerinin yapısal uygulamasının bir örneği, Şekil 1'de, gösterilmektedir. Bu birleşimlerin dayanımlarının hesaplanabilmesi için, Çelik
Yapıların Tasarım ve Yapım Kuralları (CYTYE, 2016) yönetmeliğinde herhangi bir tasarım yöntemi mevcut değildir. Ancak, düzlem kafes sistem birleşimlerin dayanımlarının hesaplama yöntemleri güncel yönetmelikte mevcuttur. $\mathrm{Bu}$ çalışma, farklı geometrik parametreler dikkate alınarak simetrik eksenel yüke maruz kalmış çok düzlemli K-birleşimlerin davranışlarını incelemek ve yönetmelikte mevcut olan yöntemin bu tip birleşimlerin dayanım hesaplamalarında güvenli ve ekonomik olarak kullanılabilirliğini incelemeyi amaçlamıştır.

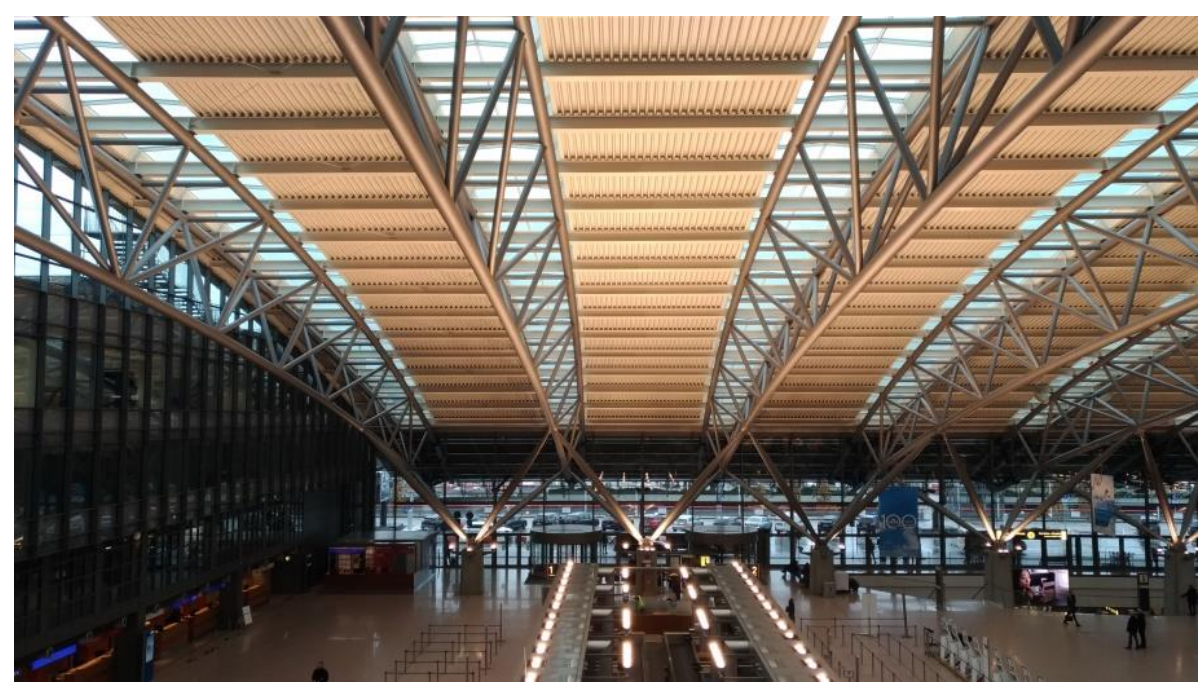

Şekil 1. Çok düzlemli K-birleşimlerine ait örnek bir havaalanı, Hamburg

Şekil 2, çok düzlemli K-birleşimin geometrik parametreleri ile tipik bir geometrik konfigürasyonunu göstermektedir. Makino vd. (1984) ve Paul (1992) çok düzlemli K-birleşimleri üzerinde çok sayıda test gerçekleştirmişlerdir. $\mathrm{Bu}$ birleşimlerin dayanımlarının hesaplanabilmesi için düzlem kafes tasarım denklemlerine bir düzeltme katsayısı eklenmesini önermişledir. Bununla birlikte, düzeltme faktörü EN 1993-1- 8'de, 0.90'dır (CEN, 2005). Bunun nedeni, örgü elemanlarındaki yüklemelerin yatay birleşenleri, başlık elemanı üzerinde ekstra eksenel gerilme yaptığı için birleşimin dayanımını düşürmektedir. $\mathrm{Bu}$ yüzden, parametrik çalışmalarda, birleşim bölgesindeki ekstra eksenel yüklemeyi önlemek için başlık elemanı ucundan dengeleyici bir eksenel yükleme yapılmıştır.

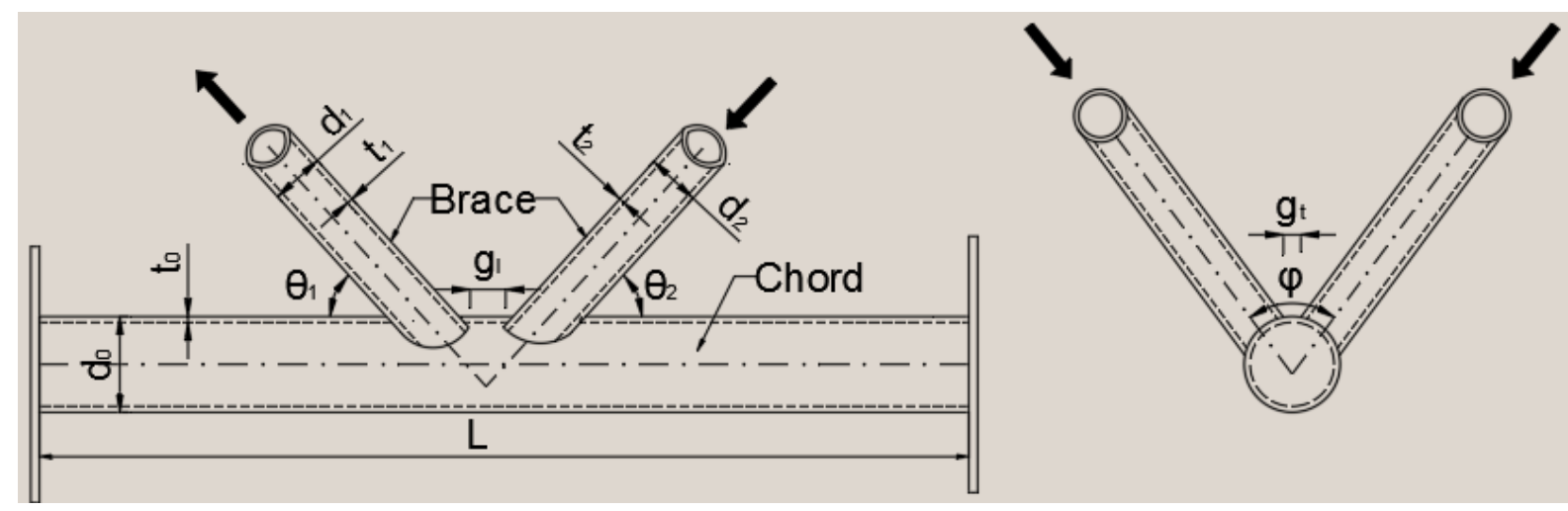

Şekil 2. Çok düzlemli K-birleşiminin geometrik parametreleri 
Çelik Yapıların Tasarım ve Yapım Kuralları (CYTYE, 2016) yönetmeliğine göre boru profillerden oluşan düzlem K-birleşiminin mevcut

$P=\frac{F_{y} t_{0}^{2}}{\sin \theta}\left(2.0+11.33 \frac{d_{2}}{d_{0}}\right) \gamma^{0.2}\left[1+\frac{0.024 \gamma^{1.2}}{e^{\left(\frac{0.5 g_{l}}{t_{0}}-1.33\right)}+1}\right]$

Bu denklemde;

$P$ : Birleşimin dayanımı

$F_{y}$ : Elemanların karakteristik akma gerilmesi

$t_{0}$ : Başlık elemanı et kalınlığ 1

$\theta$ : Başlık ve örgü elemanları arasındaki dar açı

$d_{0}$ : Başlık elemanının çapı

$d_{2}$ : Basınç kuvveti etkisindeki örgü elemanının çapı

$\gamma$ : Başlık elemanının narinlik oranı $\left(=d_{0} / 2 t_{0}\right)$

$g_{l}$ : Örgü elemanları arasındaki mesafeyi göstermektedir.

Lee ve Wilmshurst $(1995,1996)$, çok düzlemli ve ara uzaklıklı K-birleşimlerin sonlu eleman modelini, Makino vd. (1984) ve Paul (1992)'un test sonuçları ile karşılaştırarak doğrulamasını yapmışlardır. Uygun ağ aralığı, malzeme özellikleri, kaynak geometrisi ve mesnet sinır koşulları belirlendikten sonra, parametrik araştırmada çok sayıda sayısal model analizi gerçekleştirmişlerdir (Lee ve Wilmshurst, 1996). Çok düzlemli K-birleşimlerin dayanımları ve göçme modu üzerine, $\gamma\left(=\mathrm{d}_{0} / 2 \mathrm{t}_{0}\right)$ oranının etkisini incelemişlerdir. Bu birleşimlerin iki tipik

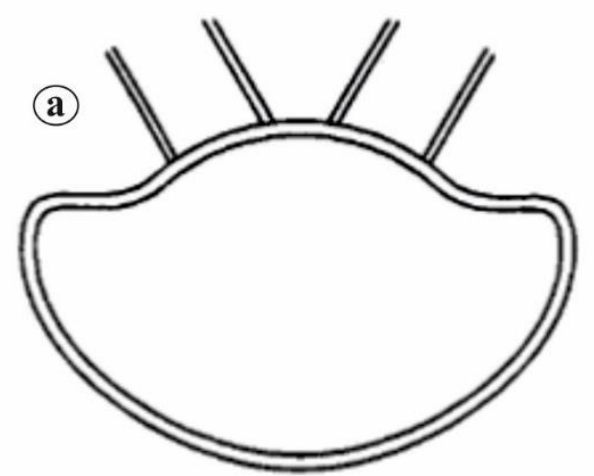

Şekil 3. Çok düzlemli K-birleşimlerin göçme modları. (a) Mod 1. (b) Mod 2. eksenel kuvvet dayanımı, denklem 1'den hesaplanabilmektedir. göçme modu, Şekil 3'te gösterildiği gibi elde edilmiştir. Sayısal analiz sonuçlarına dayanarak, düzlem dışı örgü elemanları arasındaki mesafenin, başlık eleman çapına oranı $\left(\zeta_{t}=g_{t} / d_{0}\right) 0.215$ 'den küçük olduğunda, Şekil 3 (a)'da gösterildiği gibi kesitte yatay deformasyonlar meydana gelir. Düzlem dışı örgü elemanları arasındaki aralık büyük ise, iki komşu örgü elemanı arasındaki başlık elamanı yüzünde yerel burkulma gerçekleşmektedir. $\mathrm{Bu}$ durumda ise, başlık elemanının enine kesiti Şekil 3 (b)'de gösterildiği gibi dikey olarak deforme olmuştur.

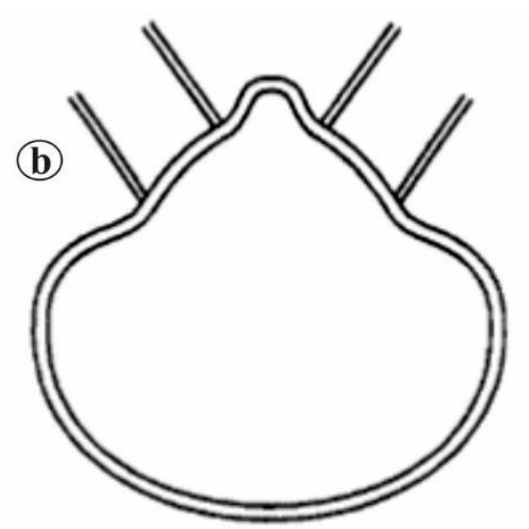

Liu vd. (2001, 2002), kutu profillerden yapılmış çok düzlemli K-birleşimleri ile düzlem Kbirleşimleri üzerine bir dizi nümerik çalışma gerçekleştirmişlerdir. Başlık elemanı üzerindeki eksenel yükün aynı olması durumunda, çok düzlemli birleşimlerin dayanımları eş değer düzlem birleşimlerinkinden büyük olduğu sonucuna ulaşılmıştır.

Dessouki vd. (2009), başlık elemanındaki eksenel yükün çok düzlemli K-birleşimlerin dayanımlarına etkileri üzerine sayısal analizler yapmışlardır. Başlık elemanına uygulanan öngermenin, birleşim dayanımını \% 50 'ye kadar azalttığı sonucuna ulaşılmıştır. Bu sorunu ortadan kaldırmak için birleşim bölgesinde takviye levhası kullanılarak dayanımının güçlendirilebileceği gösterilmiştir.

Forti vd. (2015, 2017), simetrik yüklü çok düzlemli K-birleşimleri üzerinde sayısal analizler yapmışlardır. Ancak, sayısal modellerinde kaynak 
geometrisi dikkate alınmamıştır. $\mathrm{Bu}$ nedenle, Şekil 3 'te gösterildiği gibi göçme modlarını belirleyen sınır değeri Lee ve Wilmshurst'un (1996) sonuçlarından farklıydı. Bu birleşimlerin dayanımlarını hesaplamak için yeni bir düzeltme faktörü önerdiler.

Zhao vd. (2019), çok düzlemli ve bindirmeli Kbirleşimleri üzerine hem deneysel hem de sayısal analizler gerçekleştirmişlerdir. Bu tip bindirmeli birleşimler bu çalışmada dikkate alınmamıştır. Çünkü, bindirmeli örgü elemanlarının kesimi ve kaynaklanması çok daha karmaşıktır ve maliyeti önemli derecede arttırmaktadır.

Son y1llarda, bu tip birleşimlerin güçlendirilmesine yönelik çeşitli araştırmalar yapılmıştır. Chen vd. (2015) tarafından, boru profillerden yapılmış beton dolgulu uzay kafesler üzerine dört adet test yapılmıştır. Test sonuçlarına göre, başlık elemanı üzerindeki plastik şekil değiştirmelerin önlenmesi ile birleşimlerin dayanımlarında önemli derecede artış gözlemlenmiştir. Tong vd. (2019), Kbirleşimlerindeki gerilme yığılmalarını azaltmaya yönelik deneysel bir araştırma gerçekleştirmişlerdir. Yaptıkları deneysel çalışmalarda, boru profiller, karbon fiber takviyeli polimer malzemesi ile güçlendirilmiştir. Woghiren ve Brennan (2009) ise denizaşırı yapıların yorulma ömrünü birleşim bölgelerinde takviye levhasi kullanarak arttrmay1 başarmışlardır.
Yapılan çalışmalardan görüleceği üzere, başlık elemanı üzerindeki eksenel yükün birleşimin dayanımına etkisi önemlidir. Ancak, bunun üzerine detaylı bir çalışmaya rastlanmamaktadır. Ayrıca düzlem kafes birleşimlerin aksine, çok düzlemli K-birleşimlerin iki ana göçme modu mevcuttur. $\mathrm{Bu}$ yüzden, uzay kafes ile düzlem kafes birleşimlerinin davranışları birbirinden farklı olabilir. Yapılan çalışmalar dayanımları arasında farklılıklar olabileceğini göstermektedir. $\mathrm{Bu}$ çalışma, farklı geometrik özelliklere sahip çok düzlemli K-birleşimlerin dayanımlarını incelemek ve güvenli bir tasarım yöntemi geliştirmeyi amaçlamaktadır.

\section{Sayısal Modellerin Doğrulaması}

Sayısal analizleri yapmak için doğrusal olmayan sonlu elemanlar yazılımı ABAQUS v6.17 (2017) kullanılmıştır. Parametrik çalışmalardan önce, Lee ve Wilmshurst (1996) tarafindan elde edilen çok düzlemli K-birleşimlerin sayısal sonuçları kullanılarak doğrulama çalışması yapıldı. Makino vd. (1984) ve Paul'un (1992) test sonuçlarına göre Lee ve Wilmshurst (1996) sayisal modellerini doğruladılar. Birleşimlerin malzeme özellikleri ve geometrik özelliklerindeki eksiklikler, test sonuçlarının doğrulama çalışmasında kullanılamamasındaki sebebidir.

Tablo 1, çok düzlemli K-birleşimlerinin doğrulama çalışması için gerekli olan geometrik parametrelerini özetlemektedir. Toplam on beş sayısal model oluşturulmuştur.

Tablo 1. Doğrulama çalışmasında kullanılan birleşimlerin geometrik özellikleri

\begin{tabular}{ccccc}
\hline Birleşim Numarası & $\begin{array}{c}\boldsymbol{d}_{\boldsymbol{I}} \text { ve } \boldsymbol{d}_{\boldsymbol{2}} \\
(\mathbf{m m})\end{array}$ & $\begin{array}{c}\boldsymbol{g}_{\boldsymbol{l}} \\
(\mathbf{m m})\end{array}$ & $\begin{array}{c}\boldsymbol{g}_{\boldsymbol{t}} \\
(\mathbf{m m})\end{array}$ & $\boldsymbol{\beta}_{\mathbf{m}} \boldsymbol{d}_{\boldsymbol{l}} / \boldsymbol{d}_{\boldsymbol{o}}$ \\
\hline SKK-01 & 28.8 & 18 & 33.4 & 0.24 \\
SKK-02 & 28.8 & 28 & 33.4 & 0.24 \\
SKK-03 & 28.8 & 38 & 33.4 & 0.24 \\
SKK-04 & 28.8 & 48 & 33.4 & 0.24 \\
SKK-05 & 28.8 & 58 & 33.4 & 0.24 \\
SKK-06 & 28.8 & 68 & 33.4 & 0.24 \\
SKK-07 & 38.4 & 18 & 23.6 & 0.32 \\
SKK-08 & 38.4 & 28 & 23.6 & 0.32 \\
SKK-09 & 38.4 & 38 & 23.6 & 0.32 \\
SKK-10 & 38.4 & 48 & 23.6 & 0.32 \\
SKK-11 & 38.4 & 58 & 23.6 & 0.32 \\
SKK-12 & 48.0 & 18 & 13.4 & 0.40 \\
SKK-13 & 48.0 & 28 & 13.4 & 0.40 \\
SKK-14 & 48.0 & 38 & 13.4 & 0.40 \\
SKK-15 & 48.0 & 48 & 13.4 & 0.40 \\
\hline
\end{tabular}

Yükleme ve mesnet sınır koşullarındaki simetri nedeniyle, hesaplama zamanından ve depodan tasarruf etmek için çok düzlemli K-birleşimlerin yarısı modellenmiştir. Sayısal modelde, hem 
başlık hem de örgü elemanları için, kalınlık yönünde iki elemanlı, C3D20R katı elemanlar kullanıldı. Bu tip elemanlar ile oluşturulan boru enkesitli birleşimlerin dayanımı önceki çalışmalarda da güvenli olarak modellenmiştir (Ozyurt vd., 2018a, b, 2019).

Uygun simülasyon modelini belirlemek için ağ büyüklügünün yakınsama çalışması yapılmıştır. Aynı ağ büyüklüğü daha sonra diğer tüm birleşimler için simülasyon modellerine uygulanmıştır. $\mathrm{Bu}$ yakınsama çalışması için Lee ve Wilmshurst (1996)'un SKK-01 numaral1 birleşimi seçilmiştir. Gerilmeler birleşim bölgesinde daha fazla olacağı için bu bölgelerdeki ağ büyüklüklerini birleşim bölgesinden uzak kısımlardakinin yarısı olarak seçilmesi öngörülmüştür. Şekil 4'ten görüleceği üzere, ağ büyüklüğü birleşim bölgesinde $5 \mathrm{~mm}$ ve daha küçük olduğunda yakınsama sağlanmış olur. Başlık elemanının et kalınlığ $5 \mathrm{~mm}$ olduğu için eleman ağ büyüklükleri birleşim bölgesinde elemanın et kalınlığına eşit büyüklükte ve diğer bölgelerde ise birleşim bölgesindeki eleman ă aralığı büyüklüğünün iki katı olarak belirlenmiştir. Şekil 5, çok düzlemli K-birleşimlerin tipik bir ağ yerleşimini göstermektedir.

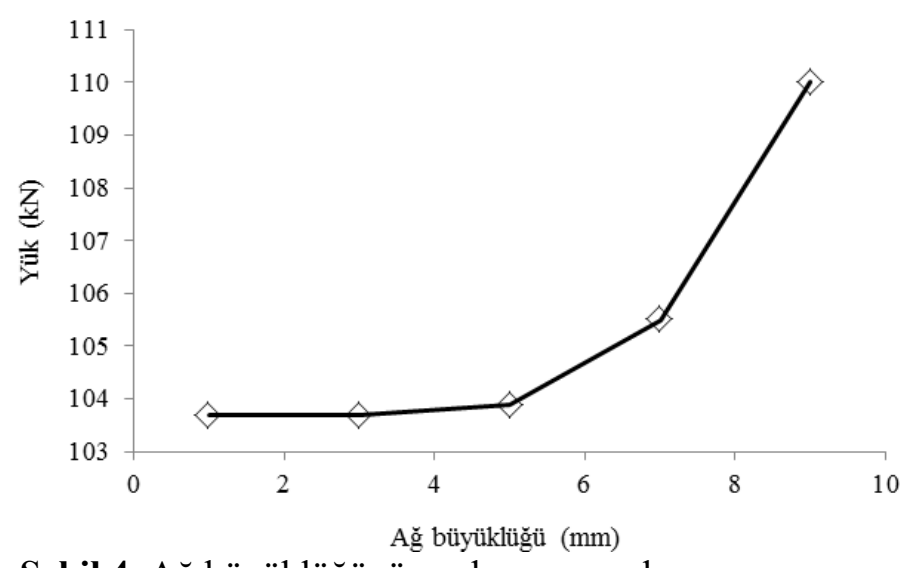

Şekil 4. Ağ büyüklüğünün yakınsama çalışması
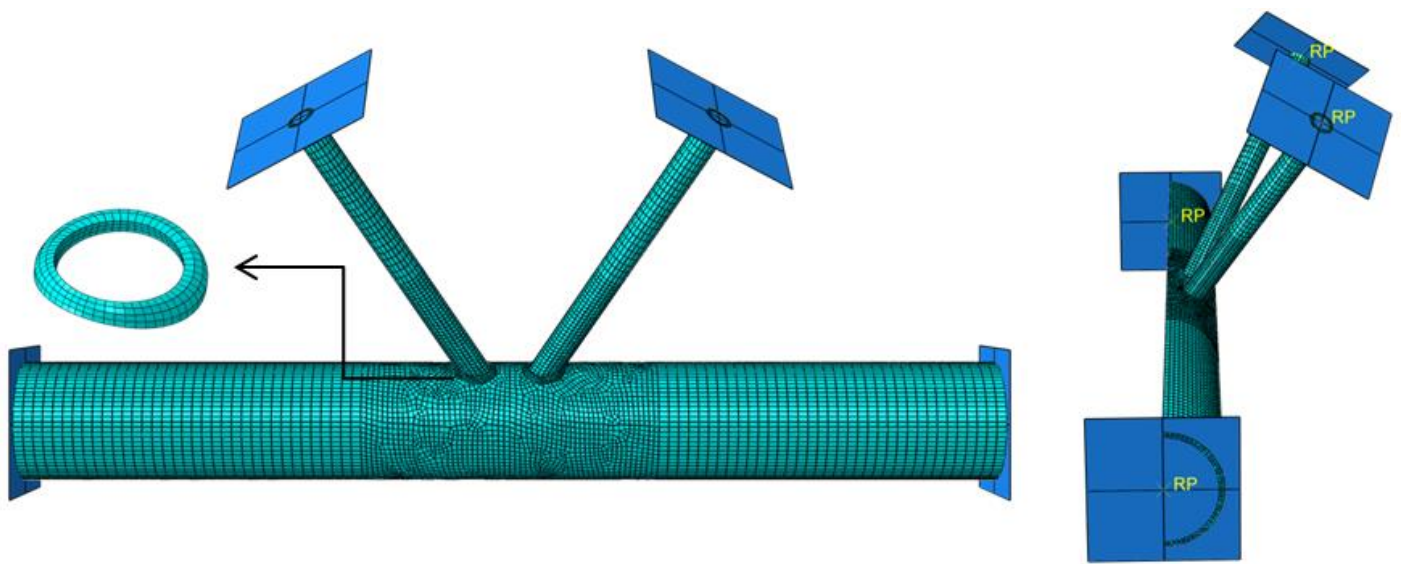

Şekil 5. Çok düzlemli K-birleşimlerin örnek bir sayısal modeli

Lee ve Wilmshurst (1996), yaptıkları çalışmada başlık ve örgü elemanları için S355 çelik sınıfını kullanılmışlardır. S355 çeliğinin; karakteristik akma gerilmesini $\left(f_{y}\right) 355 \mathrm{~N} / \mathrm{mm}^{2}$, karakteristik çekme dayanımını $\left(f_{u}\right) 510 \mathrm{~N} / \mathrm{mm}^{2}$ ve elastisite modülünü $(E) 210 \mathrm{GPa}$ 'ır. Malzeme özellikleri sayısal modellerde dikkate alınmıştır.

Sayısal modellerde, denklem 2 ve 3'ten kullanılarak elde edilen gerilme-birim uzama eğrisi kullanılmıştır (Boresi ve Schmidt, 2003). Çünkü doğrusal olmayan analizlerin gerçekleşmesi için bu dönüştürme işleminin yapılması gerekmektedir.

$\varepsilon_{T}=\ln (1+\varepsilon)$

$\sigma_{T}=\sigma \times(1+\varepsilon)$

Bu denklemlerde;

$\varepsilon$ : birim uzama oranını

$\varepsilon_{T}$ : dönüştürülmüş birim uzama oranını

$\sigma:$ gerilmeyi

$\sigma_{\mathrm{T}}$ : dönüştürülmüş gerilmeyi göstermektedir. 
Lee ve Wilmshurst (1996)'un sayssal kalibrasyon parametrelerini örnek alarak, doğrulaması yapılan çok düzlemli K-birleşimin başlık elemanı bir ucundan hareketli, diğer ucundan sabit mesnetlenmiş, yükleme yapılmayan örgü elemanının uçlarında ise tüm yer değiştirmeler kısıtlanmıştır (Şekil 6). Mesnet koşullarını tanımlamak için, eleman uçlarına rijit levhalar yerleştirilmiş ve bu levhaların merkezlerindeki referans noktaları seçilerek gerekli mesnet sınırları girilmiştir. Tüm örnek modellerde, başlık ve örgü elemanlarının et kalınlığ 1 sırasıyla, $t_{0}=5$ $\mathrm{mm}$ ve $t_{l}=4 \mathrm{~mm}$ 'dir. Düzlem dışı örgü elemanlar arasındaki açı ile başlık ve örgü elemanları arasındaki açı ise $60^{\circ}$ 'dir.

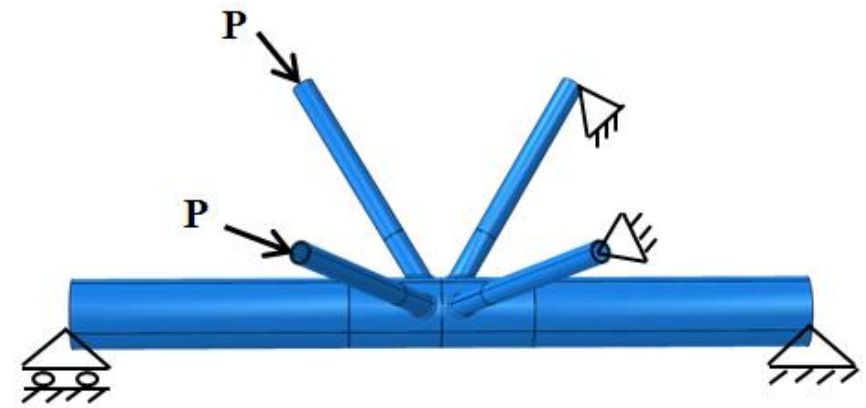

Şekil 6. Doğrulaması yapılan birleşimin mesnet koşulları

Tablo 2'de, Lee ve Wilmshurst (1996)'un sayisal sonuçlarından ve bu çalışmadaki sayısal analizlerden elde edilen çok düzlemli Kbirleşimlerinin dayanımları karşılaştırılmaktadır. Sonlu elemanlar yöntemi sonuçları ile Lee ve Wilmshurst (1996)'un nümerik sonuçları çok yakın olduğu görülebilir. Maksimum dayanım farkı \%4.7'dir. $\mathrm{Bu}$ doğrulama çalışması sonucundan, parametrik çalışmalarda oluşturulacak çok düzlemli K-birleşimlerine ait sayısal modeller doğru ve güvenilir sonuçlar vermesi öngörülmektedir.

Tablo 2. Sayısal analizler ile Lee ve Wilmshurst (1996)'un sayısal sonuçlarının karşılaştırılması

\begin{tabular}{cccc}
\hline Birleşim & $\begin{array}{c}\text { Lee ve Wilmshurst (1996) } \\
\text { Numarası }\end{array}$ & $\begin{array}{c}\text { Sayısal Sonuçlar } \\
(\mathbf{k N})\end{array}$ & $\begin{array}{c}\text { Fark } \\
(\mathbf{\%})\end{array}$ \\
\hline SKK-01 & 108.8 & 103.7 & 4.7 \\
SKK-02 & 103.6 & 101.8 & 1.7 \\
SKK-03 & 99.9 & 98.3 & 1.6 \\
SKK-04 & 99.4 & 98.5 & 0.9 \\
SKK-05 & 99.4 & 98.3 & 1.1 \\
SKK-06 & 99.1 & 97.7 & 1.4 \\
SKK-07 & 137.9 & 131.9 & 4.4 \\
SKK-08 & 126.3 & 122.2 & 3.2 \\
SKK-09 & 120.1 & 117.0 & 2.6 \\
SKK-10 & 118.5 & 116.4 & 1.8 \\
SKK-11 & 118.0 & 116.6 & 1.2 \\
SKK-12 & 159.0 & 155.9 & 1.9 \\
SKK-13 & 143.5 & 143.0 & 0.3 \\
SKK-14 & 135.4 & 133.5 & 1.4 \\
SKK-15 & 132.9 & 130.5 & 1.8 \\
\hline
\end{tabular}

\section{Parametrik Çalışmalar}

$\mathrm{Bu}$ bölümde, çok düzlemli K-birleşimlerinin dayanımlarını incelemek için çok sayıda sonlu eleman analizi yapılmıştır. Örgü elemanı çapının başlık elemanı çapına oranının $\left(\beta=d_{l} / d_{0}\right)$, başlık ve örgü elemanları arasındaki dar açının $(\theta)$ ve başlık elemanının narinlik oranının $\left(\gamma=d_{0} / 2 t_{0}\right)$ birleşimin dayanımına etkileri incelenmiştir. Tüm sayısal modellerde, başlık elemanı çapı ve uzunluğu sirasiyla $193.7 \mathrm{~mm}$ ve $2000 \mathrm{~mm}$ 'dir. Şekil 7, yükleme ve mesnet koşullarını göstermektedir. Başlık elemanına uygulanan $Q_{c}$ eksenel yükü, örgü elemanlarına uygulanan yüklemelerin yatay 
birleşenlerini karşılaması için eklenmiştir. Denklem 4 yardım ile bu değer hesaplanabilir. Böylece, başlık elemanı üzerinde ekstra oluşacak eksenel yük ortadan kaldırılmıştır. Ayrıca, birleşim bölgesinde eksentrisiteden ötürü oluşabilecek ekstra eğilme momentini ortadan kaldırmak için başlık ve örgü elemanların eksenleri hem düzlem içinde hem de düzlem dışında tek bir noktada kesişecek şekilde birleşimlerin konfigürasyonları oluşturulmuştur. Yükleme ve sınır koşullarındaki simetriden ötürü, sayısal modelin sadece yarısı kullanılarak analiz süresinden ve çıktıların depolanması yönünden tasarruf edilmiştir. Düzlem dışı örgü elemanlar arasındaki açı $60^{\circ}$ dir.

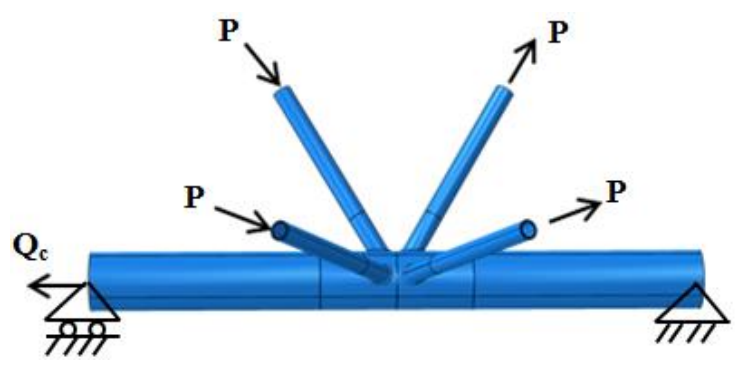

Şekil 7. Sayısal modellerin mesnet sınır koşulları ve yükleme durumu

$\mathrm{Q}_{\mathrm{c}}=4 \mathrm{P} \cos \theta \cos (60)$

Aşağıdaki geometrik parametreler dikkate alınmıştır.

$0.30 \leq \beta \leq 0.50(0.31,0.39$ and 0.46$)$

$10.0 \leq \gamma \leq 20.0(9.7,12.1,15.4$ and 19.4$)$

$30^{\circ} \leq \theta \leq 60^{\circ}\left(30^{\circ}, 45^{\circ}\right.$ and $\left.60^{\circ}\right)$

Yapılan tüm sayısal analizlerde S355 çelik sınıfi kullanılmıştır. S355 çeliğinin; karakteristik akma gerilmesi $F_{y}=355 \mathrm{~N} / \mathrm{mm}^{2}$, karakteristik çekme mukavemeti $F_{u}=510 \mathrm{~N} / \mathrm{mm}^{2}$ ' dir. Çeliğin elastisite modülü $(E) 210 \mathrm{GPa}$ ve poisson oranı $(v) 0.3$ olarak varsayılmıştır. Malzeme özelliklerinin ABAQUS girdisinde doğrulma çalışmasında yapıldığ 1 gibi parametrik çalışmalarda da Denklem 2 ve 3 yardımıyla dönüştürme yapılması ile Şekil 8'de gösterildiği gibi dönüştürülmüş gerilme-birim uzama eğrisi elde edilmiştir. Ayrıca, doğrulama çalışmasında seçilen sonlu eleman tipi C3D20R katı elemanları, parametrik çalışmalarda da kullanılmıştır.

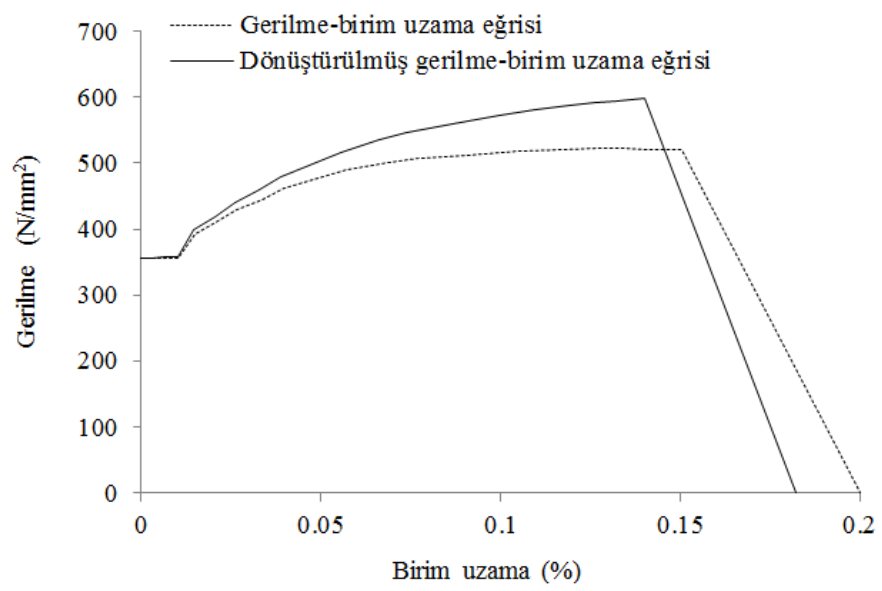

Şekil 8. S355 çelik sınıfına ait gerilme-birim uzama eğrisi

\subsection{Göçme Modları}

Bu bölümde, çok düzlemli K-birleşimlerin göçme modları incelenmiştir. Üç farklı $\beta(0.31,0.39$ and 0.46) oranı kullanılarak çok düzlemli Kbirleşimlerin göçme modları elde edilmiştir. Diğer tüm geometrik parametreler sabit tutulmuştur. Başlık elemanının narinlik oranı 15.4 ve başlık ve örgü elemanları arasındaki dar açını $60^{\circ}$ olarak seçilmiştir.

Şekil 9'da, sayısal analizlerden elde edilmiş çok düzlemli K-birleşimlerin deformasyonları gösterilmektedir. Giriş bölümünde belirtildiği gibi simetrik yüklü çok düzlemli K-birleşimlerin iki ana göçme modu vardır. Birleşim bölgesindeki 
düzlem dışı örgü elemanlar arasındaki mesafe yeteri kadar büyük ise, Şekil 9 (a)'da gösterildiği gibi, başlık elemanı en kesitinde düşey yer değiştirmeler meydana gelir. Bu tip birleşimlerde, başlık elemanı hem plastikleşmeye hem de iki örgü elemanı ile birleştiği ara mesafede yerel burkulmaya maruz kalmaktadır. Şekil 9 (b ve c)'deki birleşimlerde ise, başlık elemanı yatay yönde deformasyonların etkisindedir. Bunun sebebi, örgü elemanları arasındaki mesafenin küçük olması ve düzlem kafes sistemlerdeki $\mathrm{K}$ - birleşimlerine benzer şekilde iki düzlem dışı örgü elemanları tek bir eleman gibi çalışmasından kaynaklanmaktadır. $\mathrm{Bu}$ yüzden, bu tip birleşimlerde sadece başlık elemanında plastikleşme olmaktadır. $\mathrm{Bu}$ farklı göçme modlarının sebebi örgü elemanları arasındaki mesafedir. Eğer bu mesafe yeteri kadar büyük ise, Örgü elemanları arasındaki mesafenin küçük olması durumunda ise, yerel burkulma ortadan kalkar ve başlık elemanında plastikleşmeler meydana gelir.
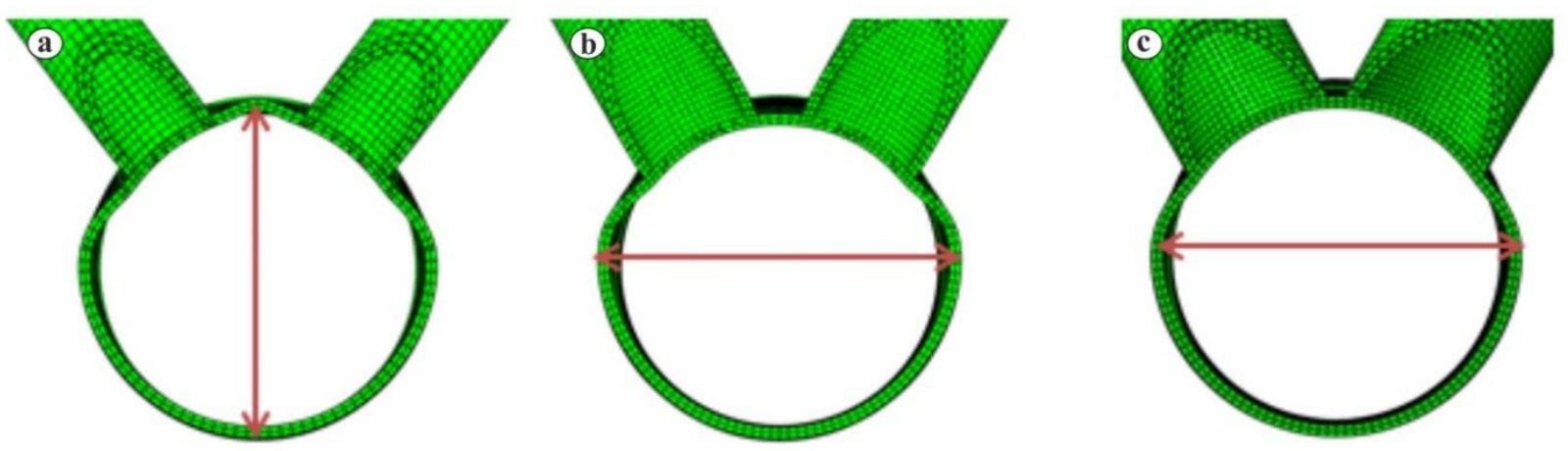

Şekil 9. Çok düzlemli K-birleşimlerin deformasyonları. (a) $\beta=0.31$. (b) $\beta=0.39$. (c) $\beta=0.46$

Bu çalışmada, şekil değiştirmeleri sınırlamak ve birleşimlerin dayanımlarını belirlemek için Lu'nun deformasyon sınırı kullanılmıştır (Lu vd., 1994). Yaygın olarak kabul gören bu deformasyon sınırı, başlık elemanı enkesitindeki şekil değiştirme çapının \%3 'ünü aşmazsa yük deformasyon eğrisindeki maksimum değer birleşimin dayanımını verir veya maksimum yük bu yer değiştirme sınırının ötesinde meydana gelirse birleşimin dayanımı başlık eleman çapının \%3'üne eşit olan şekil değiştirmeye karşılık gelen yük ile sınırlandırılır. Lu'nun deformasyon sınırı, başlık elaman yüzünün üst kısmı ile başlık elemanın merkez çizgisi arasındaki göreceli bir yer değiştirme miktarıdır.
Şekil 10'da, çok düzlemli K-birleşimlerinin yük deformasyon eğrileri karşılaştırılmıştır. Ayrıca Lu'nun deformasyon sinır1 grafikte gösterilmektedir. Şekil 10 'dan görüleceği gibi $\beta$ oranı ile birleşimin dayanımı doğru orantılıdır. Ancak birleşimlerde iki farklı göçme mekanizması olduğu için bir sonraki parametrik çalışmada geometrik parametrelerinin ve göçme modlarının birleşim dayanımı üzerindeki etkileri detaylı olarak incelenmiştir. Aynı zamanda, incelenen tüm birleşimlerin maksimum dayanımları deformasyon sinırından önce meydana geldiği için yük - deformasyon eğrilerindeki maksimum değer, birleşimin dayanımını vermektedir.

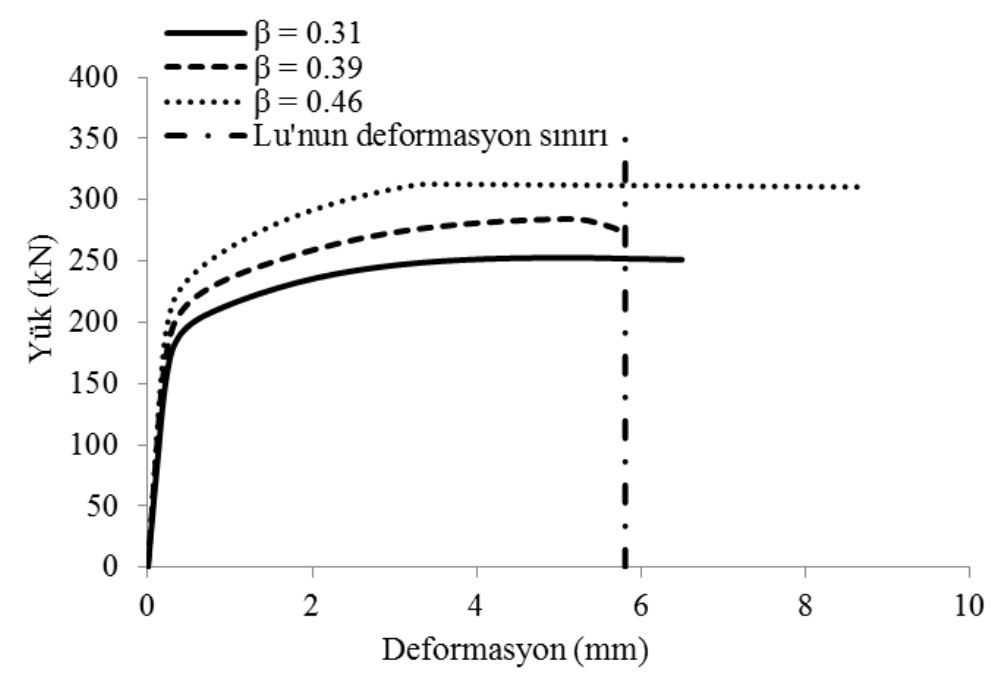

Şekil 10. Çok düzlemli K-birleşimlerinin yük- deformasyon grafiği 


\subsection{Geometrik Parametrelerin Dayanımlara Etkileri}

$\mathrm{Bu}$ kısımda, mevcut yönetmelikteki boru profillerden üretilmiş düzlem K-birleşimleri için önerilen tasarım yöntemi sayısal analizlerden elde edilen dayanımlar ile karşılaştırılmıştır. Örgü elemanı çapının başlık elemanı çapına oranının $\left(\beta=\mathrm{d}_{1} / \mathrm{d}_{0}\right)$, başlık ve örgü elemanları arasındaki dar açının $(\theta)$ ve başlık elemanının narinlik oranının $\left(\gamma=\mathrm{d}_{0} / 2 \mathrm{t}_{0}\right)$ birleşim dayanımına etkileri detaylıca incelenmiştir. KK- $\beta-\theta-\gamma$, sayısal modellerin adlandırılması için kullanılan bir ifadedir. Örneğin, KK-0.39-30-9.7, örgü elemanı çapının başlık elemanı çapına oranı 0.39 , başlık ve örgü elemanları arasındaki dar açı $30^{\circ}$ ve başlık elemanının narinlik oranı 9.7 olan çok düzlemli K-birleşimini temsil etmektedir.

Tablo 3, sayısal analiz sonuçları ile Çelik Yapıların Tasarım ve Yapım Kuralları (CYTYE, 2016) yönetmeliğine göre boru profillerden oluşan düzlem K-birleşim yöntemi (Denklem 1) kullanılarak hesaplanmış dayanımlar karşılaştırılmıştır. Karşılaştırmalardan görüleceği üzere, CYTYE (2016)'da mevcut olan düzlem Kbirleşim yöntemi kullanılarak çok düzlemli $\mathrm{K}$ birleşimlerin dayanımları güvenli olarak hesaplanabilmektedir. Ayrıca, EN 1993-1-8 (CEN, 2005)'de çok düzlemli K-birleşimlerin dayanımları düzlem K-birleşim yöntemleri ile hesaplanabilmesi önerilmektedir. Ancak, \%10'luk bir azaltma faktörünün eklenmesi gereklidir. Bunun sebebi, başlık elemanı üzerinde örgü elemanlarından kaynaklanan ekstra eksenel kuvvet birleşimin dayanımını azaltmaktadır. Tablo 3'den görüleceği üzere, sayısal analiz sonuçları her durumda, CYTYE (2016) tahminlerine göre yüksektir. Bu yüzden, azaltma faktörünün kullanılmasına gerek yoktur. Eğer başlık elemanı üzerine etkiyen ekstra eksenel yüklemeler göz önüne alınması gerekli ise, Çelik Yapıların Tasarım ve Yapım Kuralları (CYTYE, 2016) yönetmeliğinde mevcut olan başlık elemanında bağlanan yüzeyin basınç etkisinde olduğu ara uzaklıklı K-birleşimin azaltma katsayısının kullanılması gereklidir.

Tablo 3. CYTYE (2016) öngörüleri ile sayısal analiz sonuçlarının karşılaştırılması

\begin{tabular}{lccc}
\hline $\begin{array}{c}\text { Birleşim } \\
\text { Numarası }\end{array}$ & Sayısal sonuçlar $(\mathbf{k N )}$ & $\begin{array}{c}\text { CYTYE(2016) } \\
(\mathbf{k N})\end{array}$ & $\begin{array}{c}\text { Sayısal sonuçların } \\
\text { CYTYE(2016)'ye oranı }\end{array}$ \\
\hline KK-0.31-30-9.7 & 656.8 & 618.0 & 1.06 \\
KK-0.31-30-12.1 & 450.0 & 413.6 & 1.09 \\
KK-0.31-30-15.4 & 304.7 & 269.0 & 1.13 \\
KK-0.31-30-19.4 & 195.6 & 177.4 & 1.10 \\
KK-0.31-45-9.7 & 484.8 & 444.1 & 1.09 \\
KK-0.31-45-12.1 & 333.4 & 294.0 & 1.13 \\
KK-0.31-45-15.4 & 220.3 & 190.5 & 1.16 \\
KK-0.31-45-19.4 & 118.6 & 102.9 & 1.15 \\
KK-0.31-60-9.7 & 454.5 & 429.3 & 1.06 \\
KK-0.31-60-12.1 & 303.7 & 287.5 & 1.06 \\
KK-0.31-60-15.4 & 202.5 & 180.9 & 1.12 \\
KK-0.31-60-19.4 & 126.1 & 113.9 & 1.11 \\
KK-0.39-30-9.7 & 738.6 & 721.6 & 1.02 \\
KK-0.39-30-12.1 & 510.9 & 482.7 & 1.06 \\
KK-0.39-30-15.4 & 336.7 & 314.0 & 1.07 \\
KK-0.39-30-19.4 & 222.6 & 207.1 & 1.07 \\
KK-0.39-45-9.7 & 563.2 & 533.0 & 1.06 \\
KK-0.39-45-12.1 & 384.4 & 348.8 & 1.10 \\
KK-0.39-45-15.4 & 259.7 & 223.5 & 1.16 \\
KK-0.39-45-19.4 & 169.2 & 146.5 & 1.15 \\
KK-0.39-60-9.7 & 564.3 & 531.7 & 1.06 \\
KK-0.39-60-12.1 & 396.9 & 371.5 & 1.07 \\
KK-0.39-60-15.4 & 285.5 & 250.8 & 1.14 \\
KK-0.39-60-19.4 & 192.2 & 168.1 & 1.14 \\
KK-0.46-30-9.7 & 854.6 & 806.1 & 1.06 \\
KK-0.46-30-12.1 & 577.0 & 538.9 & 1.07 \\
KK-0.46-30-15.4 & 382.1 & 350.4 & 1.09 \\
\hline
\end{tabular}




\begin{tabular}{llll}
\hline KK-0.46-30-19.4 & 256.4 & 231.1 & 1.11 \\
KK-0.46-45-9.7 & 673.1 & 622.5 & 1.08 \\
KK-0.46-45-12.1 & 450.8 & 404.3 & 1.12 \\
KK-0.46-45-15.4 & 288.1 & 254.5 & 1.13 \\
KK-0.46-45-19.4 & 193.5 & 165.2 & 1.17 \\
KK-0.46-60-9.7 & 621.9 & 585.0 & 1.06 \\
KK-0.46-60-12.1 & 462.6 & 412.6 & 1.12 \\
KK-0.46-60-15.4 & 312.6 & 285.6 & 1.09 \\
KK-0.46-60-19.4 & 234.2 & 201.5 & 1.16 \\
\hline
\end{tabular}

Örgü elemanı çapının başlık elemanı çapına oranı $\left(\beta=d_{l} / d_{0}\right)$ artıkça, birleşimin dayanımı önemli derecede artmaktadır. Bunun sebebi, örgü elemanı çapının büyümesi ile birleşim bölgesinde aktarılan yük daha fazla alana sahip olmaktadır. Şekil 11, farklı $\beta$ oranına sahip çok düzlemli K- birleşimlerinin plastik deformasyonlarını göstermektedir. Çok düzlemli K-birleşimlerin plastik deformasyonları, örgü elemanları arasındaki mesafe azaldıkça birleşim bölgesinde yoğunlaşmaktadır.
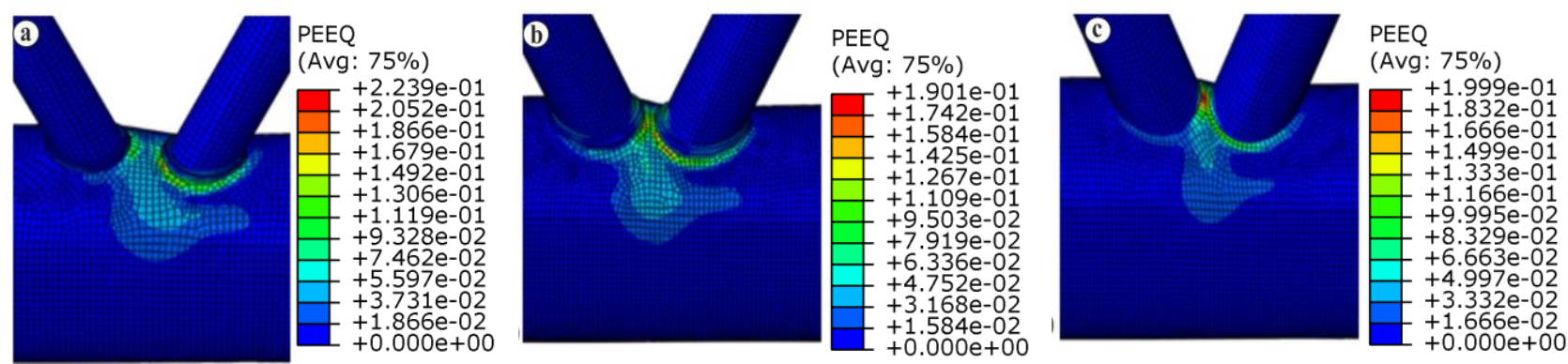

Şekil 11. Farklı $\beta$ oranına sahip çok düzlemli K-birleşimlerinin plastik deformasyonları. (a) KK-0.31-6015.4. (b) KK-0.39-60-15.4. (c) KK-0.46-60-15.4

Bir diğer geometrik parametre, başl1k ve örgü elemanları arasındaki dar açıdır $(\theta)$. Bu açı büyüdükçe, başlık elemanına yük aktarılan alan azaldığ 1 için birleşimin dayanımı azalmaktadır. Şekil 12, farklı $\theta$ açılarına sahip örgü elemanlarının çok düzlemli K- birleşimlerin başlık elemanları üzerindeki temas yüzeyleri görünmektedir. Şekil 12'den görüldüğ̈̈ üzere, açı arttıkça, başlık elemanı üzerindeki temas yüzeyi azalmaktadır ve dolayısı ile birleşimin dayanımı azalmaktadır.
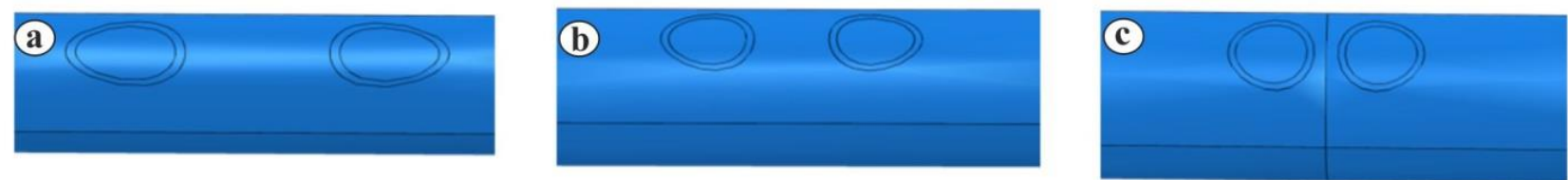

Şekil 12. Başlık elemanı üzerinde farklı açılara sahip örgü elemanlarının temas yüzeyleri. (a) KK-0.39-3015.4. (b) KK-0.39-45-15.4. (c) KK-0.39-60-15.4

\section{Sonuçlar}

Çok düzlemli K-birleşimlerin dayanımları, sonlu elemanlar modeli kullanılarak incelenmiştir. Çelik Yapıların Tasarım ve Yapım Kuralları (CYTYE, 2016) yönetmeliğinde, bu tip birleşimlerin dayanımlarının hesaplanabilmesi için herhangi bir öneri söz konusu değildir. Ancak, CYTYE (2016) düzlem kafes birleşimlerin dayanımlarını kapsamaktadır. $\mathrm{Bu}$ yüzden, sayısal modellerin doğrulama çalışması yapıldıktan sonra bir dizi parametrik çalışma gerçekleştirilmiştir. Çok düzlemli K-birleşimlerin dayanımları, sayısal analiz sonuçları ile CYTYE (2016) de belirtilen düzlem kafes K-birleşimlerin dayanım yöntemi kullanılarak elde edilen sonuçlar 
karşılaştırılmış̧ır. Bunun sonucunda, düzlem kafes birleşim yöntemlerinin aynı zamanda çok düzlemli K-birleşimleri için güvenli ve ekonomik sonuçlar verdiği tespit edilmiştir. Bu yüzden, Avrupa yönetmeliğindeki \%10'luk azaltma faktörünün kullanılmasına gerek yoktur. Ancak, bu yöntemin kullanılabilmesi için, örgü elemanları üzerindeki eksenel yüklerin yatay bileşenleri başlik elemanında ekstra gerilmelere sebep olduğundan başlık elemanı - gerilme etkileşim parametresinin dikkate alınması gereklidir. Çünkü, bu çalışma kapsamında, başlık elemanı üzerindeki ekstra gerilmeler dengeleyici bir eksenel yükleme $\left(Q_{c}\right)$ ile ortadan kaldırılmıştır.

Ayrıca, çok düzlemli K-birleşimlerin dayanımlarını belirlerken Lu'nun deformasyon sınırı dikkate alınmıştır. Tüm birleşimlerin maksimum dayanımları deformasyon sınırından önce meydana geldiği için yük - deformasyon eğrilerindeki maksimum değer, birleşimin dayanımını belirlemiştir. Uzay kafes Kbirleşimlerin iki farklı göçme modu olmasına rağmen, birleşimlerin dayanımları onların geometrik özellikleri ile ilişkilidir. Bu yüzden, çok düzlemli ve ara uzaklıklı K-birleşimlerin dayanımları denklem 1 ile hesaplanabilir.

\section{Kaynaklar}

ABAQUS, V.,2017. 6.17 documentation, Dassault Systems Simula Corporation

Boresi, A. P. ve Schmidt, R. J., 2003. Advanced Mechanics of Materials, John Wiley and Sons Press, USA.

CEN EN 1993-1-8, 2005. Design of Steel Structures, Design of Joints, British Standart Institute, London.

Chen, Y., Feng, R. ve Gao, S., 2015. Experimental Study of Concrete-filled Multiplanar Circular Hollow Section Tubular Trusses, Thin-Walled Structures, 94, 199-213.

CYTYE, Türk Standartları Enstitüsü, 2016. Çelik Yapıların Tasarım ve Yapım Kuralları, Ankara.

Dessouki, A. K., Ibrahim, S. M. ve Khalaf, M. A., 2009. The Ultimate Capacity Of Stiffened And Unstiffened Multi-Planar Tubular KK-Joints In Offshore Structures, Civil Engineering Research Magazine, Cairo, Egypt.

Forti, N. C., Requena J. A. V. ve Forti T. L., 2015. Parametric Study of Tubular KK Multiplanar Steel Connections, Journal of Constructional Steel Research, 114, 188-195.
Forti, N. C., Requena J. A. V. ve Forti T. L., 2017. Numerical Methodology for Analyses of Tubular KK Multiplanar Steel Joints, REMInternational Engineering Journal, 157-165.

Lee, M. ve Wilmshurst, S., 1995. Numerical Modelling of CHS Joints with Multiplanar Double-K Configuration, Journal of constructional steel research, 32, (3), 281-301.

Lee, M. ve Wilmshurst S.,1996. Parametric Study of Strength of Tubular Multiplanar KK-joints, Journal of Structural Engineering, 122, (8), 893904.

Liu, D. ve Wardenier, J., 2001. The Strength of Multiplanar Gap KK-joints of Rectangular Hollow Sections Under Axial Loading, The Eleventh International Offshore and Polar Engineering Conference, Stavanger, Norway.

Liu, D. ve Wardenier, J., 2002. The Strength of Multiplanar Overlap KK-joints of Rectangular Hollow Sections Under Axial Loading. The Twelfth International Offshore and Polar Engineering Conference, Kitakyushu, Japan.

Lu, L. H., De Winkel, G. D., Yu, Y. ve Wardenier J., 1994. Deformation Limit for the Ultimate Strength of Hollow Section Joints, Proceedings of the Sixth International Symposium on Tubular Structures, Melbourne, Australia.

Makino, Y., Kurobane Y. ve Ochi K., 1984. Ultimate Capacity of Tubular Double K-joints, Proceedings of the 2nd International Institute of Welding Conference on Welding of Tubular Structure, Pergamon Press Tarrytown, NY.

Ozyurt, E., 2018a. Yanginda Elips Enkesitli Eksenel Yük Taşıyan Çelik Kolonların Davranışı, Uludağ Üniversitesi Mühendislik Fakültesi Dergisi, Bursa, 23, 1, 205-206.

Ozyurt, E.; Wang, Y. C., 2018b. Resistance of Axially Loaded T-and X-Joints of Elliptical Hollow Sections at Elevated Temperatures-A Finite Element Study. In: Structures. Elsevier, 15-31.

Özyurt, E. and Yılmaz, M., 2019. Düzlem İçi Eğilme Momenti Altındaki Elips Enkesitli Tbirleşimlerinin Dayanımları, Gümüşhane Üniversitesi Fen Bilimleri Enstitüsü Dergisi, 9(3), 547-556.

Paul, J. C., 1992. The Ultimate Behavior of Multiplanar TT-and KK-joints Made of Circular Hollow Sections, PhD thesis, Kumanmoto University, Japan.

Tong, L., Xu, G., Zhao, X.-L., Zhou, H. ve Xu, F., 2019. Experimental and Theoretical Studies on Reducing Hot Spot Stress on CHS Gap K-joints 
with CFRP Strengthening, Engineering Structures, 201, 1-17.

Woghiren, C. ve Brennan, F. P., 2009. Weld Toe Stress Concentrations in Multi-planar Stiffened Tubular KK Joints, International Journal of Fatigue, 31, 164-172.
Zhao, X., Qiu, S., Hu, K., Sivakumaran, K. S. ve Chen, Y., 2019. Capacity of Multi-planar Out-of-plane Overlapped Tubular KK-joints Having Different Joint Details, Journal of Constructional Steel Research, 158, 182-200. 